\title{
Pengaruh Kepuasan Pelanggan dan Loyalitas Pelanggan Terhadap Word of Mouth (Studi Kasus di Cafe Come On Coffe Pomalaa)
}

\author{
Andry Stepahnie Titing, Almansyah Rundu Wonua, Hendrik, Muhammad Dzulfaqar \\ Abd. Al-Haq ${ }^{4}$ \\ Universitas Sembilanbelas November Kolaka \\ andrysteph@gmail.com
}

\begin{abstract}
Abstrak
Tujuan penelitian untuk mengetahui bagaimana pengaruh kepuasan pelanggan dan loyalitas pelanggan terhadap word of mouth Pelanggan Come On Coffee. Populasi dalam riset ini adalah pelanggan Come On Coffee. Pengambilan sampel pada riset ini dilakukan menggunakan kuesioner dengan menggunakan metode purposive sampling. Metode analisis data yang digunakan pada penelitian ini yaitu SEM (Structural Equation Model) dengan menggunakan SmartPLS. Hasil penelitian menujukkan bahwa kepuasan pelanggan dan loyalitas pelanggan berpengaruh positif dan signifikan terhadap word of mouth..
\end{abstract}

Kata Kunci: kepuasan pelanggan, loyalitas pelanggan, word of mouth, dan come on coffee

\begin{abstract}
The purpose of this study was to determine the effect of customer satisfaction and customer loyalty on word of mouth Come on Coffee customers. The population used in this research is the customers of the Come on Coffee. Sampling method in this research was conducted by questionnaire and by used purposive sampling method. Data analysis method used in this study is SEM (Structural Equation Model) using SmartPLS. The results showed that customer satisfaction and customer loyalty had a positive and significant effect on word of mouth
\end{abstract}

Keywords: customer satisfaction, customer loyalty, word of mouth, come on coffee

\section{PENDAHULUAN}

Beberapa tahun terakhir bisnis cafe berkembang pesat, oleh sebab itu menjadi hal biasa apabila ditemukan bisnis cafe di kota-kota kecil seperti di wilayah Pomalaa Kabupaten Kolaka Provinsi Sulawesi Tenggara. Menjamurnya bisnis cafe di kota-kota kecil disebabkan terjadi perubahan gaya hidup dan perilaku masyrakat. Dimana masyarakat terutama kategori generasi milenial senang bersosialiasi dan menghabiskan waktu di cafe, untuk nongrong, mengerjakan tugas- tugas sekolah atau tugas kampus dan biasa dijadikan sebagai tempat pertemuan untuk membahas sebuah pekerjaan atau tempat melakuan arisan keluarga.

Fenomena tersebut menjadi sebuah peluang bisnis sehingga sebagian orang yang memiliki modal lebih berusaha untuk berbisnis di bidang cafe. Come On Coffee (COC) merupakan salah satu cafe yang ada di Pomalaa Kabupaten Kolaka yang berusaha memanfaatkan peluang bisnis tersebut. Banyaknya bisnis cafe yang tumbuh dan berkembang menyebabkan Come On Coffee harus 
bersaing secara ketat dengan pesaingpesaingnya yang bergerak dibidang usaha sejenis. Masalah terpenting yang dihadapi Come On Coffee adalah memastikan keuntungan jangka panjang bagi usahanya dan dapat bertahan dalam menghadapi persaingan. Namun demikian untuk dapat bersaing Come On Coffee harus memiliki strategi yang tepat dalam mempromosikan usahanya sehingga mampu menarik dan mempertahankan pelanggan.

Word of mouth (WOM) atau biasa disebut dengan promosi dari mulut ke mulut merupakan salah satu strategi di dalam pemasaran (Ahmad et al., 2014; Aries et al., 2018; Kurniawan, 2012; Sanger, 2013). Selanjutnya menurut Sarin \& Pal (2014); Joesyiana (2018) menjelaskan bahwa Word of mouth berdampak langsung pada penjualan, sehingga Word of mouth berfungsi sebagai indikator utama kesuksesan sebuah usaha. Hal ini disebabkan pemasaran melalui komunikasi word of mouth lebih dapat diandalkan daripada teknik pemasaran lainnya karena hanya $14 \%$ yang melihat atau mendengarkan iklan bisnis. $90 \%$ orang bergantung pada keluarga, teman atau kolega mereka dalam mencari tahu terkait suatu produk atau layanan yang diinginkannya (Jalilvand et al., 2013).

Naz, (2014) mengungkapkan bahwa masyarakat memiliki kecenderungan sebelum membeli, mengkosumsi atau memanfaatkan suatu produk atau layanan, hal pertama yang dilakukan yaitu mencari informasi terlebih dahulu terkait produk dan layanan tersebut. Kemudian menurut Bolang (2019) menjelaskan bahwa informasi yang diberikan pelanggan lain biasanya dianggap lebih terpercaya dibandingkan dengan promosi yang dilakukan oleh perusahaan bisnis. Bahkan apabila resiko yang diperoleh seorang pelanggan semakin besar dalam membeli sebuah produk atau jasa, maka pelanggan akan lebih aktif mencari informasi dan mereka akan lebih percaya terhadap informasi yang bersumber dari mulut ke mulut (word of mouth) untuk membantu mereka dalam memutuskan untuk membeli barang dan jasa tersebut. Beberapa penelitian sebelumnya menjelaskan bahwa word of mouth mempunyai pengaruh terhadap sikap dan keputusan pelanggan dalam melakukan pembelian (Abubakar \& Ilkan, 2016; Basri et al., 2016; Bolang, 2019; Joesyiana, 2018).

Informasi yang berasal dari Word of Mouth merupakan dampak atau konsukuensi dari kepuasan pelanggan terhadap barang dan jasa tersebut (Hsu, 2018; Murpraptomo et al., 2019; Purbandari et al., 2018). Kemudian menurut Naz (2014); Rizqulloh \& Elida, (2015); Satmoko et.al (2016) menjelaskan bahwa pada saat konsumen telah merasakan kualitas pelayanan serta merasakan kepuasan terhadap produk dan layanan yang diberikan, maka pelanggan tersebut akan membuat pujian yang baik dan menyebarkan informasi positif terkait produk dan layanan yang didapatkannya. Oleh karena itu word of mouth merupakan dampak yang dihasilkan dari sikap loyalitas pelanggan. Sebagaimana pendapat Ngoma \& Natale (2019); Srivastava \& Rai, (2018) loyalitas pelanggan cenderung mengarah pada sikap dan perilaku positif seperti melakukan pembelian berulang dan merekomendasi sebuah produk atau layanan sehingga dapat memengaruhi pelanggan lainnya.

Berdasarkan penjelasan di atas, maka penulis tertarik untuk meneliti bagaimana pengaruh kepuasan pelanggan dan 
loyalitas pelanggan terhadap word of mouth.

\section{Kepuasan Pelanggan}

Kepuasan pelanggan yaitu respon emosional yang berhubungan dengan pengalaman-pengalaman terhadap pembelian produk atau jasa (Tjiptono, 2014). Kepuasan pelanggan merupakan salah satu faktor pendorong utama dalam menghubungkan perusahaan dengan pelanggan dalam waktu jangka panjang (Kotler \& Armstrong, 2017). Lebih lanjut Kotler \& Amstrong menjelaskan kepuasan maupun ketidakpuasan, merupakan kondisi perasaan senang ataupun kecewa setelah membandingkan atas kinerja suatu produk terhadap keinginan pribadi. Kemudian menurut Giese dan Cote dalam Imanuel dan Tanoto (2017) menjelaskan bahwa kepuasan pelanggan merupakan respon pelanggan terkait apakah pelanggan merasa sangat puas terhadap produk yang dipilihnya.

Menurut Lupiyoadi (2001), ada berapa faktor yang sangat mempengaruhi tingkat kepuasan pelanggan, yaitu:

a. Kualitas Produk

Pelanggan akan merasa puas apabila berdasarkan hasil evaluasi mereka menunjukkan bahwa produk yang mereka gunakan berkualitas. Konsumen rasional selalu menuntut produk yang berkualitas untuk setiap pengorbanan yang dilakukan untuk memperoleh produk tersebut. Dalam hal ini, kualitas produk yang baik akan memberikan nilai tambah di benak konsumen.

b. Kualitas pelayanan

Kualitas pelayanan terutama dibidang jasa, pelanggan akan merasa puas bila mereka mendapatkan pelayanan yang baik atau yang sesuai dengan yang diharapkan. Pelanggan yang puas akan menunjukkan kemungkinan untuk kembali membeli produk yang sama. Pelanggan yang puas cenderung akan memberikan persepsi terhadap produk perusahaan.

c. Emosional

Pelanggan akan merasa bangga dan mendapatkan keyakinan bahwa orang lain akan kagum terhadap dia bila menggunakan produk dengan merek tertentu yang cenderung mempunyai tingkat kepuasan yang lebih tinggi. Kepuasan yang diperoleh. Bukan karena kualitas dari produk tetapi nilai sosial atau self esteem yang membuat pelanggan menjadi puas terhadap merk tertentu.

d. Harga

Produk yang mempunyai kualitas yang sama tetapi menetapkan harga yang relatif murah akan memberikan nilai yang lebih tinggi kepada pelanggannya.

\section{Loyalitas Pelanggan}

Loyalitas Pelanggan merupakan sebuah keputusan yang ditunjukkan oleh pelanggan tanpa paksaan untuk terus berlangganan terhadap produk atau jasa layanan perusahaan tertentu dalam jangka waktu begitu lama (H. Lovelock \& Wirtz, 2011). Tjiptono dan Chandra (2018) menyatakan loyalitas pelanggan sebuah komitmen pelanggan/konsumen terkait sebuah merek, toko, dan pemasok, dengan menujukkan sikap positif secara konsisten untuk melakukan pembelian ulang. Kotler dan Keller (2012) menjelaskan bahwa loyalitas pelanggan adalah kondisi yang ditunjukkan oleh pelanggan secara konsisten dalam membeli produk atau layanan dari penjual yang sama. Kemudian menurut Chrestina 
et al., (2017) loyalitas merupakan suatu sikap positif pelanggan terhadap suatu produk maupun pada perusahaan itu sendiri yang disertai dengan komitmen untuk membeli produk dan merekomendasikannya pada orang lain.

$$
\text { Kotler dan Keller (2012:57) }
$$

Adapun indikator loyalitas pelanggan yaitu:

1) Repeat Purchase (kesetian tehadap pembelian produk)

2) Retention (Ketahanan terhadap pengaruh negatif mengenai perusahaan)

3) Referalls (Mereferensikan secara total eksitensi perusahaan)

\section{Word Of Mouth}

Word of mouth communication (WOM) atau komunikasi dari mulut ke mulut adalah proses kegiatan komunikasi dalam bentuk rekomendasi baik secara individu atau kelompok terkait suatu produk atau jasa dengan tujuan untuk memberikan informasi secara individu (Kotler \& Keller, 2012). Menurut American Word of Mouth Marketing Association (WOMMA) dalam Sarin \& Pal (2014) menjelaskan bawha word of mouth secara umum dapat diartikan sebagai tindakan konsumen dalam memberikan sebuah informasi kepada konsumen lain. Menurut Bolang (2019) pemasaran WOM adalah komunikasi lisan, tertulis, dan secara elektronik antara orang-orang yang berkaitan dengan keunggulan/kualitas atau pengalaman dalam membeli/menggunakan produk atau layanan jasa. Bisanya rekomendasi atau saran yang diberikan dari pelanggan lainnya dianggap lebih terpercaya daripada kegiatan promosi yang berasal dari perusahaan. Bahkan, semakin besar risikonya pelanggan merasa dalam membeli layanan, semakin aktif mereka mencari dan mengandalkan dari mulut ke mulut (WOM) untuk membantu mereka membuat keputusan.

Dua kelompok komunikasi word of mouth menurut Hughes (2015:31), yaitu :

1) Word Of Mouth positif, merupakan proses penyampaian informasi dari mulut ke mulut yang dilakukan oleh individu yang satu ke individu lain berdasarkan pengalaman yang bersifat positif terhadap suatu produk, jasa, maupun perusahaan.

2) Word Of Mouth negatif, merupakan proses interaksi dari mulut ke mulut yang didasarkan pada pengalaman negatif yang diperoleh dari individu yang satu ke individu yang lain terhadap suatu produk, jasa, atau perusahaan

Indikator word of mouth menurut Sumardy (2011) adalah sebagai berikut:

1) Membicarakan : Kemauan seseorang untuk membicarakan hal-hal positif tentang kualitas produk/jasa kepada orang lain. Konsumen berharap mendapatkan kepuasan yang maksimal dan memiliki bahan menarik untuk dibicarakan dengan orang.

2) Merekomendasikan : Konsumen menginginkan produk yang bisa memuaskan dan memiliki keunggulan dibandingkan dengan yang lain, sehingga bisa di rekomendasikan kepada orang lain.

3) Mendorong : Dorongan terhadap teman atau relasi untuk melakukan transaksi atas produk dan jasa. Konsumen menginginkan timbal balik yang menarik pada saat mempengaruhi orang lain untuk memakai produk atau jasa yang telah diberitahukan

Menurut Babin (2015) indikator Word Of Mouth adalah sebagai berikut : 
1) Kemauan konsumen dalam membicarakan hal - hal positif tentang kualitas pelayanan dan produk kepada orang lain.

2) Rekomendasi jasa dan produk perusahaan kepada orang lain.

3) Dorongan terhadap teman atau relasi untuk melakukan pembelian terhadap produk dan jasa perusahaan.

\section{Pengaruh Kepuasan Pelanggan Terhadap Loyalitas Pelanggan}

Persaingan bisnis yang semakin ketat, masalah terpenting yang dihadapi pebisnis adalah menyediakan produk dan layanan jasa yang berkualitas tinggi untuk meningkatkan kepuasan pelanggan sehingga pelanggan tetap setia untuk tidak pindah keproduk atau layanan lainnya. Kim dan Lee (2011) dalam (Taghizadeh et al., 2013) menjelaskan bahwa pada saat pelanggan merasa puas terhadap produk atau layanan suatu perusahaan maka ada kecenderungan untuk setia pada perusahaan tersebut. Kepuasan merupakan kondisi perasaan senang ataupun kecewa setelah membandingkan atas kinerja suatu produk dengan harapan individu. Jika kinerjanya kurang dari harapannya maka pelanggan akan mengalami kekecewaan dan jika sesuai dengan harapannya maka pelanggan akan merasa puas. Perusahaan yang berfokus terhadap kepuasan pelanggan bisa meningkatkan loyalitas pelanggan dan di waktu yang bersamaan akan membantu perusahaan untuk memiliki citra yang positif (Felix, 2018). Sebagaimana hasil penelitian (Haile, 2018; Thungasal, 2019) Kepuasan pelanggan berpengaruh positif terhadap loyalitas pelanggan. Kemudian menurut Hardiansyah (2012) Refleksi loyalitas dari pelanggan yang puas akan terjadi dalam bentuk pembelian ulang, testimoni positif mengenai produk, dan rekomendasipilihan produk kepada orang lain Berdasarkan hal tersebut hipotesis dalam penelitian ini adalah sebagai berikut:

H1 : Kepuasan pelanggan berpengaruh secara positif terhadap loyalitas pelanggan.

\section{Pengaruh Kepuasan Pelanggan Terhadap Word Of Mouth}

Rahmawati dan Suminar, (2014) kepuasan pelanggan merupakan faktor penting dalam mempengaruhi words of mouth yang positif. Pelanggan yang merasa puas terhadap kulitas produk atau layanan, tidak segan-segan mengungkapkan perasaan senangnya pada orang lain terkait produk atau layanan tersebut. Sehingga membuat orang lain terpengaruh ingin mengetahui sekaligus merasakan apa yang dikatakan oleh pelanggan tersebut. Hal tersebut mendorong terjadinya words of mouth. Words of mouth merupakan bentuk promosi yang tidak perlu mengeluarkan biaya karena dilakukan secara lisan atau tertulis, di mana pelanggan yang merasa puas akan memberi tahu orang lain betapa mereka menyukai produk atau jasa layanan yang dikeluarkan oleh perusahaan (Sarin \& Pal, 2014). Word of mouth mendorong penjualan karena percakapan tentang merek memiliki dampak yang kuat pada orang. Lebih dari setengah kepercayaan pelanggan sangat tinggi terhadap informasi yang mereka dengar selama percakapan Word of Mouth. Berdasarkan hal tersebut hipotesis dalam penelitian ini adalah sebagai berikut:

H2 : Kepuasan pelanggan berpengaruh secara positif terhadap word of mouth 


\section{Pengaruh Loyalitas Pelanggan Terhadap Word Of Mouth}

Sebuah usaha harus mampu menjaga hubungan yang sifatnya jangka panjang dengan pelanggannya, pelanggan yang memiliki loyalitas akan memberikan manfaat secara finansial dan keberhasilan usaha- Pelanggan yang memiliki sikap loyal bisa dijadikan sebagai maskot dalam menyebarkan informasi positif kepada calon pelanggan lainnya (Rahmawati \& Suminar, 2014): Word of mouth merupakan dampak yang dihasilkan dari sikap loyalitas pelanggan. Berdasarkan hal tersebut hipotesis dalam penelitian ini adalah sebagai berikut:

H3: Loyalitas pelanggan berpengaruh secara positif terhadap word of mouth

\section{METODOLOGI}

Penelitian ini menggunakan pendekatan kuantitaif, dengan tujuan untuk mencari pengaruh antar satu variabel atau lebih dengan variabel lainnya yaitu antara variabel bebas dan variabel terikat. Adapun yang menjadi variabel bebas yaitu kepuasan pelanggan (X1) dan Loyalitas Pelanggan (X2) sedangkan yang menjadi variabel terikat yaitu Word of Mouth (Y).

Populasi dalam penelitian ini adalah pelanggan Come On Coffee (COC). Dalam penelitian ini menggunakan purposive sampling untuk menentukan responden penelitian. Purposive sampling yaitu metode penetapan responden untuk dijadikan sampel berdasarkan pada kriteria tertentu (Siregar, 2013). Adapun kriteria sampel dalam penelitian ini yaitu, pelanggan $\mathrm{COC}$ yang sudah berkunjung lebih dari dua kali. Data penelitian dikumpulkan dengan menggunakan kuisioner. Kemudian data yang dikumpulkan dianalisis secara statistik menggunakan pendekatan Structural Equation Model (SEM) dengan bantuan program SmartPLS (Partial Least Square) versi M2

\section{HASIL DAN PEMBAHASAN \\ Pengujian Model Pengukuran (Outer Model)}

Pengujian outer model dilakukan untuk memastikan bahwa pengukuran yang digunakan dalam penelitian bisa digunakan sebagai alat pengukuran. Oleh karena itu tujuan dari pengujian outer model yaitu untuk melihat validity (validitas) dan reliability (reliabilitas) alat ukur.

\section{Uji Validitas}

Untuk mengetahui valid atau sah sebuah kuisioner yang digunakan dalam penelitian maka dilakukan uji validitas. Menurut (Ghozali, 2014) menjelaskan bahwa nilai indikator valid atau tidaknya dapat diketahui melalui nilai convergent validty, discriminant validity, atau AVE dimana skala pengukuran dengan nilai loading 0.5 sampai 0.60 maka dianggap cukup.

Tabel 1. Hasil Uji Convergent Validity (Nilai Outer Loading)

\begin{tabular}{cccc}
\hline & $\begin{array}{c}\text { Kepuasan } \\
\text { Pelanggan } \\
(\mathrm{X} 1)\end{array}$ & $\begin{array}{c}\text { Loyalitas } \\
\text { Pelanggan } \\
(\mathrm{X} 2)\end{array}$ & $\begin{array}{c}\text { Word Of } \\
\text { Mouth } \\
(\mathrm{Y})\end{array}$ \\
\hline X1.1.1 & $\mathbf{0 , 8 3 1}$ & & \\
X1.1.2 & $\mathbf{0 , 8 8 9}$ & & \\
X1.1.3 & $\mathbf{0 , 9 1 7}$ & & \\
X1.1.4 & $\mathbf{0 , 9 4 8}$ & & \\
X1.2.1 & $\mathbf{0 , 9 2 6}$ & & \\
X1.2.2 & $\mathbf{0 , 9 5 6}$ & & \\
X1.2.3 & $\mathbf{0 , 9 2 1}$ & & \\
X1.2.4 & $\mathbf{0 , 8 7 1}$ & & \\
X1.3.1 & $\mathbf{0 , 9 2 0}$ & \\
X1.3.2 & $\mathbf{0 , 8 6 7}$ & & \\
X1.3.3 & $\mathbf{0 , 9 1 5}$ & & \\
X1.4.1 & $\mathbf{0 , 8 8 0}$ & &
\end{tabular}




\begin{tabular}{llll} 
X1.4.2 & $\mathbf{0 , 9 7 2}$ & & \\
X1.4.3 & $\mathbf{0 , 9 4 0}$ & & \\
X2.1.1 & & $\mathbf{0 , 7 1 0}$ & \\
X2.1.2 & & $\mathbf{0 , 9 3 5}$ & \\
X2.1.3 & & $\mathbf{0 , 9 3 0}$ & \\
X2.2.1 & & $\mathbf{0 , 9 0 4}$ & \\
X2.2.2 & & $\mathbf{0 , 9 0 2}$ & \\
X2.3.1 & & $\mathbf{0 , 9 8 3}$ & \\
X2.3.2 & & $\mathbf{0 , 9 3 6}$ & \\
Y.1.1 & & & $\mathbf{0 , 9 3 4}$ \\
Y.1.2 & & & $\mathbf{0 , 9 0 9}$ \\
Y.1.3 & & & $\mathbf{0 , 9 0 6}$ \\
Y.2.1 & & & $\mathbf{0 , 9 1 3}$ \\
Y.2.2 & & & $\mathbf{0 , 9 6 0}$ \\
Y.2.3 & & & $\mathbf{0 , 9 3 5}$ \\
Y.2.4 & & & $\mathbf{0 , 8 1 5}$ \\
Y.2.5 & & & $\mathbf{0 , 7 9 5}$ \\
Y.3.1 & & & $\mathbf{0 , 9 3 3}$ \\
Y.3.2 & & & $\mathbf{0 , 9 2 3}$ \\
Y.3.3 & & $\mathbf{0 , 9 4 3}$ \\
Y.3.4 & & $\mathbf{0 , 9 2 1}$ \\
\hline & &
\end{tabular}

Sumber: Hasil Pengolahan Data Primer

Hasil analisas convergent validity menujukkan seluruh item indikator memiliki nilai $>0,5$ maka dapat dinyatkan valid dan telah memenuhi persyaratan uji validitas konvergen (convergent validity), sebagaimana menurut pendapat Chin dalam Ghozali (2014, hal 39) bahwa nilai outer loading antara 0,5 - 0,6 telah dianggap cukup memenuhi prasyratan convergent validity.

Selain outer loading kriteria lain yang dapat digunakan untuk uji validitas adalah dengan melihat nilai Average Variance Extracted (AVE)

Tabel 2. Average Variance Extracted (AVE)

\begin{tabular}{cc}
\hline Variabel & $\begin{array}{c}\text { Average Variance } \\
\text { Extracted } \\
\text { (AVE) }\end{array}$ \\
\hline Kepuasan Pelanggan $\left(\mathrm{X}_{1}\right)$ & 0,761 \\
Loyalitas Pelanggan $\left(\mathrm{X}_{2}\right)$ & 0,765
\end{tabular}

Word of Mouth (Y)

0,777

Sumber: Hasil Pengolahan Data Primer

Berdasarkan Nilai Average

Variance Extracted (AVE) pada tabel 2 menujukkan nilai AVE masing-masing variabel penelitian dimana untuk variabel kepuasan pelanggan nilai AVE sebesar 0,761 , variabel loyalitas pelanggan nilai AVE sebesar 0,765 dan variabel word of mouth nilai AVE sebesar 0,777. Berdasarkan nilai AVE ketiga variabel tersebut maka dapat disimpulkan telah memenuhi prasyaratan untuk uji convergent validity karena nilai AVE ketiga variabel diatas 0.5 .

\section{Uji Reliabilitas}

Tahap selanjutnya adalah uji reabilitas. Uji reliabilitas dimaksudkan untuk mengetahui konsistensi suatu konstruk penelitian. Uji reliabilitas dilakukan dengan melihat nilai Composite Reliability dan Cronbach's Alpha. Adapun hasil uji reliabilitas dapat dilihat pada tabel 3 dan 4 berikut:

Tabel 3. Nilai Composite Reliabilility

\begin{tabular}{lc}
\hline \multicolumn{1}{c}{ Variabel } & $\begin{array}{c}\text { Composite } \\
\text { Reliability }\end{array}$ \\
\hline Kepuasan Pelanggan $\left(\mathrm{X}_{1}\right)$ & 0,977 \\
Loyalitas Pelanggan $\left(\mathrm{X}_{2}\right)$ & 0,957 \\
Word of Mouth $(\mathrm{Y})$ & 0,977 \\
\hline
\end{tabular}

Sumber: Hasil Pengolahan Data Primer

Berdasarkan nilai composite reliability menujukkan bahwa variabel kepuasan pelanggan memiliki nilai composite reliability sebesar 0,977, variabel loyalitas pelanggan memiliki nilai composite reliability sebesar 0,957 dan variabel word of mouth memiliki nilai sebesar 0,977. Ketiga variabel menujukkan nilai composite reliability di atas 0,7 sehingga dapat disimpulkan bahwa semua konstruk pada model 
penelitian yang diukur telah memenuhi kriteria. Hal ini menjelaskan bahwa ketiga variabel memiliki reliabilitas yang baik untuk masing-masing konstruknya.
Adapun model struktural dapat dilihat pada gambar 1 .

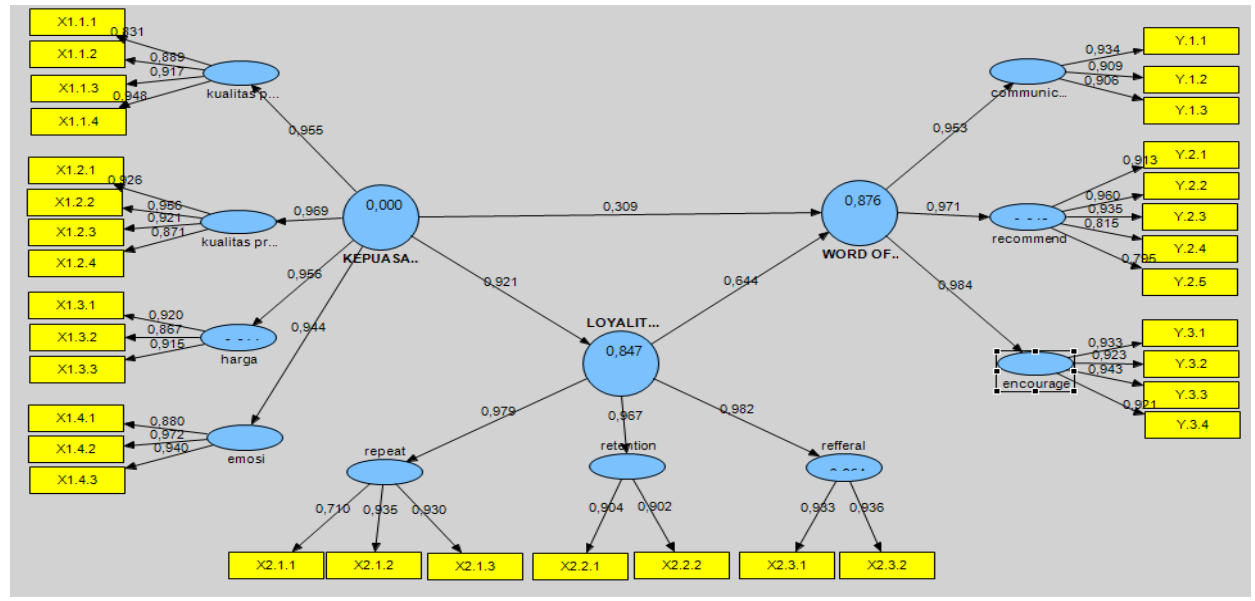

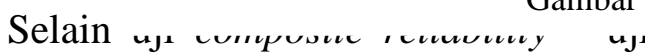
reliabilitas juga dapat dilakukan dengan melihat hasil uji cronbach's alpha. Adapun hasil uji cronbach's alpha dapat dilihat pada tabel berikut.

Tabel 4. Nilai Cronbachs Alpa

\begin{tabular}{lc}
\hline \multicolumn{1}{c}{ Variabel } & $\begin{array}{c}\text { Cronbachs } \\
\text { Alpa }\end{array}$ \\
\hline Kepuasan Pelanggan $\left(\mathrm{X}_{1}\right)$ & 0,975 \\
Loyalitas Pelanggan $\left(\mathrm{X}_{2}\right)$ & 0,947 \\
Word of Mouth $(\mathrm{Y})$ & 0,973 \\
\hline
\end{tabular}

Sumber: Hasil Pengolahan Data Primer

Berdasarkan tabel 4. diatas menujukkan bahwa ketiga variabel penelitian memiliki nilai cronbach's alpha diatas 0,7 hal ini dapat disimpulkan bahwa masing-masing variabel memiliki reliabilitas yang baik.

\section{Pengujian Model Struktural (Inner Model)}

Inner model merupakan model struktural untuk melihat nilai R-Square dan melihat nilai signifikansi T-statistik dalam rangka uji hipotesis penelitian.

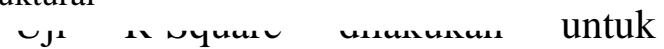
mengukur seberapa besarnya pengaruh variabel terikat dipengaruhi oleh variabel bebas. Berdasarkan pengolahan data nilai R-Square dapat ditujukkan pada tabel 5 berikut.

Tabel 5. R-Square

\begin{tabular}{lc}
\hline Variabel & R-Square \\
\hline Loyalitas Pelanggan $\left(\mathrm{X}_{2}\right)$ & 0,847 \\
Word of Mouth (Y) & 0,876 \\
\hline \multicolumn{2}{c}{ Sumber: Hasil Pengolahan Data Primer }
\end{tabular}

Berdasarkan tabel 5 menjelaskan bahwa variabel kepuasan pelanggan mempengaruhi variabel loyalitas pelanggan sebesar 0,847 maka dapat disimpulkan bahwa variabel kepuasan pelanggan mampu menjelaskan variabel loyalitas pelanggan sebesar $84,7 \%$ kemudian sisanya $15,3 \%$ dapat dijelaskan oleh variabel-variabel lainnya yang tidak ada dalam penelitian ini. Selanjutnya variabel kepuasan pelanggan dan variabel loyalitas pelanggan mampu menjelaskan variabel word of mouth sebesar 0,876 artinya variabel kepuasan 
pelanggan dan loyalitas pelanggan mampu menjelaskan variabel word of mouth sebesar $87,6 \%$ kemudian sisanya $12,4 \%$ dijelaskan oleh variabel lainnya yang tidak ada dalam penelitian ini.

Hasil R-Square menujukkan nilai diatas 0,6 sehingga dikategorikan dalam nilai baik. Hal ini sebagaimana pendapat Chin dalam Ghozali (Ghozali, 2014) nilai R-Square diatas 0,67 termasuk dalam kategori baik.

\section{Uji Hipotesis}

Pengujian hipotesis dilakukan untuk menujukkan sejauh mana pengaruh variabel independen terhadap variabel dependen, dengan cara membandingkan nilai T-statistik atau T-hitung dengan $\mathrm{T}$ tabel. Hipotesis diterima apabila T-hitung lebih besar (>) dari T-tabel. T-tabel diperoleh dari nilai degree of freedom (df), peneliti menggunakan rumus agregat (n-k) dimana $\mathrm{n}=$ banyak observasi atau jumlah responden sedangkan $\mathrm{k}=$ banyaknya variabel independen (bebas) dan variabel dependen (terikat), sehingga $\mathrm{n}-\mathrm{k}=43-3=40$. Sehingga didapatkan nilai $\mathrm{T}$-tabel $=1,684$ dengan taraf signifikansi 5\% $(0,05)$.

Tabel 1. Uji Hipotesis

\begin{tabular}{cccccc} 
& & pelanggan & $\left(\mathrm{X}_{1}\right)$ & dengan & loyalitas \\
\hline & $\begin{array}{c}\text { Original } \\
\text { Sample (O) }\end{array}$ & $\begin{array}{c}\text { Sample } \\
\text { Mean (M) }\end{array}$ & $\begin{array}{c}\text { Standard } \\
\text { Deviation } \\
\text { (STDEV) }\end{array}$ & $\begin{array}{c}\text { Standard } \\
\text { Error } \\
\text { (STERR) }\end{array}$ & $\begin{array}{c}\text { T statistics } \\
\text { (Io/SterrI) }\end{array}$ \\
\hline $\begin{array}{c}\text { Kepuasan Pelanggan -> } \\
\text { Loyalitas Pelanggan } \\
\text { Kepuasan Pelanggan -> } \\
\quad \text { Word Of Mouth }\end{array}$ & 0,920 & 0,919 & 0,017 & 0,017 & 53,050 \\
$\begin{array}{c}\text { Loyalitas Pelanggan -> } \\
\text { Word Of Mouth }\end{array}$ & 0,644 & 0,314 & 0,104 & 0,104 & 2,966 \\
\hline
\end{tabular}

Sumber: Hasil Pengolahan Data Primer Tahun 2020

\section{Pengujian Hipotesis Pertama Pengaruh Kepuasan Pelanggan Terhadap Loyalitas Pelanggan}

Berdasarkan hasil uji hipotesis menunjukkan ada hubungan secara signifikan antara kepuasan pelanggan $\left(\mathrm{X}_{1}\right)$ dengan loyalitas pelanggan $\left(\mathrm{X}_{2}\right)$ dimana nilai T-statistik sebesar 53,050 > T-tabel 1,684. Kemudian nilai original sample estimate menujukkan nilai positif yaitu sebesar 0,920 hal ini menjelaskan arah hubungan diantara kepuasan pelanggan $\left(\mathrm{X}_{2}\right)$ yaitu berhubungan positif. Maka dapat disimpulkan hipotesis H1 dalam penelitian ini yang menyatakan bahwa kepuasan pelanggan berpengaruh positif terhadap loyalitas pelanggan diterima.

\section{Pengujian Hipotesis Kedua Pengaruh Kepuasan Pelanggan Terhadap Word Of Mouth (WoM)}

Berdasarkan hasil uji hipotesis menunjukkan ada hubungan secara signifikan antara kepuasan pelanggan $\left(\mathrm{X}_{1}\right)$ dengan word of mouth $(\mathrm{Y})$ dimana nilai T-statistik sebesar 2,966 > T-tabel 1,684. Kemudian nilai original sample estimate menujukkan nilai positif yaitu sebesar 0,309 hal ini menjelaskan bahwa 
arah hubungan diantara kepuasan pelanggan $\left(\mathrm{X}_{1}\right)$ dengan Word Of Mouth (Y) yaitu berhubungan positif. Maka dapat disimpulkan hipotesis $\mathrm{H} 2$ dalam penelitian ini yang menyatakan bahwa kepuasan pelanggan berpengaruh positif terhadap word of mouth diterima.

Pengujian Hipotesis Ketiga Pengaruh Loyalitas Pelanggan Terhadap Word Of Mouth (WoM)

Berdasarkan hasil uji hipotesis menunjukkan ada hubungan secara signifikan antara loyalitas pelanggan $\left(\mathrm{X}_{2}\right)$ dengan word of mouth (Y) karena nilai $\mathrm{T}$ statistik sebesar 6,264> T-tabel 1,684. Kemudian nilai original sample estimate menujukkan nilai positif yaitu sebesar 0,644 hal ini menjelaskan bahwa arah hubungan antara loyalitas pelanggan $\left(\mathrm{X}_{2}\right)$ dengan word of mouth (Y) yaitu berhubungan positif. Maka dapat disimpulkan $\mathrm{H} 3$ dalam penelitian ini yang menyatakan bahwa loyalitas pelanggan berpengaruh positif terhadap word of mouth (Y)diterima.

\section{Analisis Kepuasan Pelanggan Terhadap Loyalitas Pelanggan}

Kepuasan pelanggan memiliki pengaruh positif dan signifikan terhadap loyalitas pelanggan cafe COC. Hipotesis tersebut menyatakan terdapat pengaruh positif kepuasan pelanggan terhadap loyalitas pelanggan cafe COC. Hal ini menujukkan bahwa layanan, produk serta harga yang ada di cafe COC sudah sesuai harapan dari pelanggan, dan berdampak terhadap kepuasan pelanggan. Sehingga dengan meningkatnya kepuasan pelanggan maka akan meningkatkan kesetiaan pelanggan untuk kembali ke cafe COC. Penelitian ini sesuai dengan penelitian terdahulu yang dilakukan Herdiansyah, (2014); Lyana (2016); Marlin, (2017) bahwa kepuasan pelanggan dapat mencipatkan loyalitas pelanggan agar tidak berpindah terhadap produk atau jasa yang lainnya.

\section{Analisis Kepuasan Pelanggan Terhadap Word Of Mouth (WOM)}

Kepuasan pelanggan berpengaruh positif dan signifikan terhadap word of mouth Pelanggan cafe COC. Hipotesis yang menyatakan terdapat pengaruh positif kepuasan pelanggan terhadap word of mouth pelanggan cafe COC. Hal ini menujukkan bahwa ada kesan positif yang dimunculkan oleh pengelolah cafe COC dalam upaya memberikan kepusan kepada pelanggannya, sehingga kesan positif tersebut membuat pelanggan cafe COC untuk merekomendasikan atau mempromosikan COC kepada orang lain. Hal ini didukung hasil penelitian yang dilakukan oleh Hsu, (2018); Murpraptomo et al., (2019); Purbandari et al., (2018); Sanjaya \& Yasa, (2018) bahwa Kepuasan pelanggan mempengaruhi word of mouth.

\section{Analisis Loyalitas Pelanggan Terhadap Word Of Mouth (WOM)}

Hasil pengujian hipotesis ketiga menujukkan bahwa loyalitas Pelanggan memiliki pengaruh terhadap word of mouth. Hal ini menunjukan bahwa pengelolah cafe COC mampu menjaga loyalitas pelanggannya, dengan cara meningkatkan kualitas produk dan layanan sesuai selera pelanggannya, dan harga produk yang ditawarkan di cafe COC murah sesuai dengan kemampuan pelanggan, karena harga produk mempunyai peran penting dalam mempengaruhi pelanggan cafe $\mathrm{COC}$ untuk kembali mengkomsumsi produkproduk yang ada di cafe COC, hal ini disebabkan masyarakat Pomalaa Kabupaten Kolaka merupakan golongan 
menengah kebawah, sehingga dalam memilih atau membeli suatu produk atau jasa salah satu pertimbangan utamanya adalah harga produk atau layanan jasa tersebut. Sehingga kualitas produk dan harga produk merupakan hal-hal yang menjadi bahan perbincangan antara pelanggan dan pelanggan yang memiliki loyalitas akan merekomendasikan atau mempromosikan cafe COC kepada orang lain untuk memilih cafe COC sebagai tempat untuk menghabiskan waktu (nongkrong). Penelitian ini didukung hasil penelitian Kazemi et al., (2013); Rahmawati \& Suminar, (2014) bahwa Loyalitas Pelanggan mempnuyai pengaruh terhadap Word Of Mouth.

\section{DAFTAR PUSTAKA}

1. Abubakar, A. M., \& Ilkan, M. (2016). Impact of online WOM on Destination Trust and Intention to Travel: A Medical Tourism Perspective. Journal of Destination Marketing and Management. https://doi.org/10.1016/j.jdmm.2015. 12.005

2. Ahmad, N., Vveinhardt, J., \& Ahmed, R. R. (2014). Impact of Word of Mouth on Consumer Buying Decision. European Journal of Business and Management, Vol.6 (31).

3. Aries, M., Sunarti, \& Mawardi, M. K. (2018). Pengaruh Word Of Mouth Terhadap Minat Beli Serta Dampaknya Pada Keputusan Pembelian (Survei Pada Make up Artist yang Membeli dan Menggunakan Produk KRYOLAN di Kabupaten Bojonegoro). Jurnal Administrasi Bisnis (JAB), Vol. 60.

4. Babin, B. (2015). Modelling Consumer

\section{SIMPULAN}

Berdasarkan hasil penelitian yang telah dilakukan diperoleh kesimpulan

1) Kepuasan pelanggan berpengaruh signifikan terhadap loyalitas pelanggan cafe Come On Coffee (COC).

2) Kepuasan pelanggan berpengaruh signifikan terhadap word of mouth pelanggan Come On Coffee (COC).

3) Loyalitas pelanggan berpengaruh signifikan terhadap word of mouth pelanggan Come On Coffee (COC).

Satisfaction and Word Of Mouth: Restaurant Patronage In Korea. The Journal Of Service Marketing, Vol 19 No., 133 - 139.

5. Basri, N. A. H., Ahmad, R., Anuar, F. I., \& Ismail, K. A. (2016). Effect of Word of Mouth Communication on Consumer Purchase Decision: Malay upscale restaurant. Procedia - Social and Behavioral Sciences.

6. Bolang, J. R. D. (2019). The Effect of Advertising and E-WoM on Brand Loyalty through Brand Image: Study on VIVO brand mobile users in Malang City. The International Journal of Business \& Management. https://doi.org/10.24940/theijbm/201 9/v7/i7/bm1907-074

7. Chrestina, O. A., Rahadhini, M. D., \& Sriwidodo, U. (2017). Anteseden Kepuasan Dalam Membentuk Loyalitas Pelanggan. Benefit Jurnal Manajemen Dan Bisnis, Volume 2.

8. Felix, R. (2018). ). Service quality and customer satisfaction in selected 
banks in Rwanda. Journal of Business \& Financial Affairs, VI(1), 246-256.

9. Ghozali, I. (2014). Structural Equation Modeling-Metode Alternatif dengan Partial Least Squares (PLS). Universitas Diponogoro.

10. H. Lovelock, C., \& Wirtz, J. (2011). Services Marketing: People, Technology, Strategy, 7th edition. In Pearson.

11. Haile, A. (2018). Factors Affecting Customer Loyalty in Banks: The Case of Commercial Bank of Ethiopia. The International Journal Of Business \& Management.

12. Hardiansyah, M. F., \& Nugroho, S. S. (2012). Pengaruh Kualitas Layanan Toko Terhubung Terhadap Kepuasan dan Loyalitas Pelanggan. Benefit Jurnal Manajemen Dan Bisnis, Volume 16.

14. Herdiansyah, H. (2014). Metodologi Penelitian Kualitatif untuk Ilmu-ilmu Sosial. Salemba Humanika.

15. Hsu, L. C. (2018). Investigating Effect Of Service Encounter, Value, and Satisfaction On Word Of Mouth: An Outpatient Service Context. International Journal of Environmental Research and Public Health. https://doi.org/10.3390/ijerph150101 32

16. Imanuel, B. H., \& Tanoto, S. (2017). Pengaruh Kualitas Layanan Terhadap Kepuasan Pelanggan Di PT Hastaco Tour and Travel. AGORA, Vol. 7.

17. Jalilvand, M. R., Ebrahimi, A., \& Samiei, N. (2013). Electronic Word of Mouth Effects on Tourists' Attitudes Toward Islamic Destinations and Travel Intention: An Empirical Study in Iran.
Procedia - Social and Behavioral Sciences.

https://doi.org/10.1016/j.sbspro.2013 .06 .465

18. Joesyiana, K. (2018). Pengaruh Word Of Mouth Terhadap Keputusan Pembelian Konsumen Pada Media Online Shop Shopee Di Pekanbaru. (Survey pada Mahasiswa Semester VII Jurusan Pendidikan Akuntansi Fakultas Keguruan dan Ilmu Pendidikan Universitas Islam Riau). Jurnal Valuta, Vol. 4.

19. Kazemi, A., PaEmami, V. M., Abbaszadeh, A., \& Pourzamani, J. (2013). Impact of Brand Identity on Customer Loyalty and Word of Mouth Communications, Considering Mediating Role of Customer Satisfaction and Brand Commitment. (Case Study: Customers of Mellat Bank in Kermanshah). International Journal of Academic Research in Economics and Management Sciences. https://doi.org/10.6007/ijarems/v2i $4 / 1$

20. Kotler, P., \& Armstrong. (2017). Principles of Marketing. Pearson.

21. Kotler, P., \& Keller, K. L. (2012). Marketing Management. Essex: Pearson Education Inc.

22. Kurniawan, I. (2012). Word Of Mouth Communication Effect Of Use Of The Service Review. Jurnal Entreprenuer, Volume 3.

23. Lupiyoadi, R. (2001). Manajemen Pemasaran Jasa: Teori dan Praktek. Salemba Empat.

24. Lyana, L. (2016). Pengaruh Kualitas Pelayanan dan Nialai Pelanggan Terhadap LoyalitasPelanggan Melalui Kepuasan Emosional Pada Pelanggan Anna Face dan Body Care Centre Sarawak. Jurnal 
Manajemen.

https://doi.org/10.26460/jm.v6i1.203

25. Marlin, S. (2017). Analisis Pengaruh Kualitas Layanan Dan Kualitas Produk Terhadap Kepuasan Dan Loyalitas Pelanggan Layanan Data 4G: Studi Kasus PT. Internux. Operation Excellence Journal of Aplied Industrial Engineering, Volume 9.

26. Murpraptomo, S. H., Yuliati, L. N., \& Sartono, B. (2019). The Influence of Marketing MIX, Perceived Risk, and Satisfaction on Word of Mouth In XYZ Clinic. Journal of Consumer Sciences. https://doi.org/10.29244/jcs.4.1.1324

27. Naz, F. (2014). Word of Mouth and Its Impact on Marketing. International Journal of Scientific and Research Publications.

28. Ngoma, M. (2019). Word Of Mouth Communication: A Mediator Of Relationship Marketing and Customer Loyalty. Cogent Business \& Management, Volume 6.

29. Purbandari, E., Sugandini, D., \& Sutiono, H. T. (2018). Word Of Mouth Sebgaia Konsekuensi Kepuasan Pelanggan. Jurnal Manajemen Dan Pemasaran Jasa. https://doi.org/10.25105/jmpj.v11i1. 2355

30. Rahmawati, Y., \& Suminar, B. (2014). Pengaruh Kepuasan dan Loyalitas Pelanggan Terhadap Word of Mouth Pada Pelanggan Honda Motor Di Surabaya. Journal of Business and Banking. https://doi.org/10.14414/jbb.v4i1.29 0

31. Rizqulloh, F., \& Elida, T. (2015). Pengaruh Kualitas Pelayanan, Word
Of Mouth, Dan Loyalitas Pelanggan Terhadap Niat Pembelian Kembali Pada Bukalapak.Com. Jurnal Ilmiah Ekonomi Bisnis, Volume 20.

32. Sanger, C. A. N. (2013). The Effect Of Traditional And Electronic Word-Of-Mouth On Purchase Decision. Jurnal EMBA, Vol.1 No.4. 33. Sanjaya, D. P. W., \& Yasa, N. N. K. (2018). The Effect of Service Quality on Customer Satisfaction, Positive Word of Mouth and Corporate Image. IOSR Journal of Business and Management, Volume 20(7).

34. Sarin, C., \& Pal, B. (2014). Word of Mouth Marketing: Consumers Participation. The International Journal Of Business \& Management.

35. Satmoko, T. D., Djoko, H., \& Ngatno. (2016). Pengaruh Kualitas Pelayanan Terhadap Word Of Mouth, Melalui Kepercayaan Dan Kepuasan Konsumen Sebagai Variabel Intervening Pada Star Clean Car Wash Semarang. Jurnal Administrasi Bisnis (JIAB), Volume 5.

36. Siregar, S. (2013). Metode Penelitian Kuantitatif. Dilengkapi Dengan Perbandingan Perhitungan Manual \& SPSS. Kencana.

37. Srivastava, M., \& Rai, A. K. (2018). Mechanics of engendering customer loyalty: A conceptual framework. IIMB Management Review. https://doi.org/10.1016/j.iimb.2018.0 5.002

38. Sumardy. (2011). The Power Of Word Of Mouth Marketing.

39. Taghizadeh, H., Taghipourian, M. J., \& Khazaei, A. (2013). The effect of 
customer satisfaction on word of mouth communication. Research Journal of Applied Sciences, Engineering and Technology. https://doi.org/10.19026/rjaset.5.469 8

40. Thungasal, C. (2019). Pengaruh Kualitas Layanan dan harga Terhadap Loyalitas Pelanggan
Melalui Kepuasan Pelanggan Pada hotel Kasuari. Agora, Volume $7 \mathrm{~N}$.

41. Tjiptono, F. (2014). Pemasaran Jasa Prinsip, Penerapan, dan Penelitian. Andi.

42. Tjiptono, F., \& Chandra, G. (2018). Manajemen Kualitas Jasa. Andi. https://doi.org/10.12691/jbms-4-4-1 